\title{
Underpinning a new approach to predicting blow-up fire events
}

\author{
$\underline{\text { R.H.D. McRae }}^{\text {a }}$ \\ ${ }^{a}$ School of Science, UNSW Canberra, Australia \\ Email:r.mcrae@adfa.edu.au
}

\begin{abstract}
Extreme wildfires and their associated blow-up fire events (BUFEs) are rapidly increasingly in their frequency and impacts in eastern Australia and elsewhere. It is becoming essential that predictive capabilities keep up with this. A previously developed model, the Blow-Up Fire Outlook (BUFO) model was based on analyses of case studies of single events or small clusters of events.

During Black Summer, from October 2019 to early February 2020, in eastern Australia over 9 million hectares of forest burnt, with much of that due to extreme wildfire and about a quarter due to BUFEs. Nearly two hundred BUFEs have been identified from that season. The scale of this permitted the acquisition of a database of conditions under which BUFEs did or did not occur, allowing the addressing of selection bias and confirmation bias arising from past reliance on case studies.
\end{abstract}

The database, Population Ecology of Bushfires during Black Summer (PEBBS) covers six classes of data. PEBBS has some issues concerning completeness and data errors, which are being addressed. Weather observations cover a wide range of fire weather variables, including Drought Factor and pressure patterns, Radiosonde data, based on an archive of skew-T/log-P charts, addresses both the stability profile and key indices. Terrain data covers detailed analytical data describing the terrain and the potential influences on fire behaviour patterns. Near real-time remote sensing data includes imagery from radar, airborne and satellite sensors. Contextual data describes diverse aspects of the climatic dynamics surrounding the activity. Fire data describes classification of fire behaviour indicating the presence or absence of BUFEs or pyroCbs and their interlinkages.

Examples showing the application of PEBBS data are presented covering: pressure patterns; smoke depth; convective caps; and a hotspot transect of a BUFE. PEBBS supports: analysis of regional patterns; percentile rankings; timelines; and fire outcome options. PEBBS is supporting the development of BUFO2, a new version of the BUFO predictive model, that incorporates many new learnings from Black Summer. The PEBBS approach supports both successful incident management and rapid scientific analysis of fires to facilitate learning of lessons.

Keywords: Blow-up fire event, pyroCb, datasets, Black Summer, prediction 


\section{INTRODUCTION}

An extreme wildfire can be defined as one that on one or more occasions develops a blow-up fire event (BUFE), where the fire couples with the atmosphere above (Sharples, et al., 2016). This may produce radically different fire behaviour compared to that due to surface fuel, weather, and terrain. The ever-increasing frequency and impacts, described by Sharples et al. (2016), Di Virgilio et al. (2019) and Peterson et al. (2021), of these events make it important that predictive tools are developed.

Past predictive work on these events, such as the Blow-Up Fire Outlook (BUFO) model of McRae \& Sharples (2013 \& 2014), has focussed on data from case studies covering one or a few events. Detailed case studies, such as McRae et al. (2015), have proved useful but have suffered from being based on limited circumstances. This leaves them inherently prone to selection bias due to the small sample size or confirmation bias due to the limited scope to rigorously test elements from a still expanding set of hypotheses.

Black Summer, and especially the Australian New Year Super Outbreak described by Peterson et al. (2021), produced a large number of BUFEs and pyroCbs distributed over large geographic and temporal spans. Many more fires did not become extreme. At the same time contextual data from a range of different sources was being collected. For the first time this allows BUFEs to be studied from a holistic perspective, using population ecology concepts.

These data fall into six classes. Those classes are: (1) contextual data; (2) weather observations; (3) radiosonde profile data; (4) terrain data; (5) remote sensing data; and (6) fire data. For the elements of each class, it is possible to consider: the need for the data; the data itself; the sources; any caveats associated with the use of the data; and post-processing results.

Together these have been collated into a collection called Population Ecology of Bushfires during Black Summer (PEBBS). There are issues with PEBBS concerning completeness and data errors which are being addressed, however PEBBS provides a valuable insight into BUFE predictability.

\section{DATA}

Weather observations: Primarily these were sourced from Bureau of Meteorology (BoM) as (mainly) half hourly observation records, especially temperature $\left(\mathrm{T},{ }^{\circ} \mathrm{C}\right)$, dew point $\left(\mathrm{Td},{ }^{\circ} \mathrm{C}\right)$, relative humidity $(\mathrm{RH}, \%)$, rainfall $(\mathrm{RF}, \mathrm{mm})$, wind speed $(\mathrm{WSp}, \mathrm{km} / \mathrm{hr})$, wind direction, and air pressure $(\mathrm{QNH}, \mathrm{hPa})$. These were stored as: raw data; thematic maps (T, Td, RH, WSp, QNH, RF, DF, FFDI); and intelligence graphics (T, Td, RH, WSp, QNH, RF, FMI, FFDI) highlighting values beyond certain thresholds, such as WSp over $25 \mathrm{~km} / \mathrm{hr}$ indicating potential for vorticity-driven lateral spread (VLS) to occur and fuel moisture content below 5\% indicating easy spotfire formation (McRae \& Sharples, 2013 \& 2014). Additionally, daily data on Drought Factor (DF) was acquired. While the application of most items is straightforward, some are of interest. QNH produces a different pattern to MSLP as a trough approaches. The QNH pattern of wind vectors and dry air suggests significant contributions to BUFE formation. It must be noted that fire agency Portable Automatic Weather Stations are not well sited, especially for wind data, and skew regional-scale analyses.

Radiosonde data: These were sourced from BoM flights (via University of Wyoming, http://weather.uwyo.edu/upperair/sounding.html) and fire service flights (NSW Rural Fire Service and ACT Rural Fire Service). Skew-T - log-P graphics were stored. Key points (from surface (s), and the $850 \mathrm{hPa}$ and $700 \mathrm{hPa}$ pressure levels) were archived: Ts, Tds, T850, T700, Td850, LCL, convective cap near the LCL (CAP, ${ }^{\circ} \mathrm{C}$ ), and dew point depression near the LCL (DPD, $\left.{ }^{\circ} \mathrm{C}\right)$. The CAP indicates the degree to which the rise of a plume is impeded or blocked by the temperature gradients of the air through which it is attempting to pass. The profile types were classified as inverted "V" (dry adiabatic processes only below the LCL), dry inverted "V" (dew point depression with height below the LCL), large CAP (typically a subsidence inversion), unstable (usually linked with precipitation), and atypical (usually due to stacked, unmixed air masses). These data have a crucial role to play in BUFE "taxonomy". Five years ago, Australia had no confirmed BUFEs in a foehn wind, yet PEBBS shows that nearly half of the Black Summer BUFEs were of that type. So BUFEs are occurring in both ascending and descending air flows, and the distinction - derived from pressure charts and radiosonde flights - is critical to successful and safe incident management outcomes.

Terrain data: The traditional elevation, slope and aspect data have long been widely available. Also included were: VLS-prone lands, ruggedness class, meso-scale elevation residual, and wind regime (HighFire Risk project: www.highfirerisk.com.au). Operational experience indicates that escalated fires in Australia in rugged landscapes (local elevation range over $300 \mathrm{~m}$ ) are never extinguished unless they leave that landscape, or it rains. Knowing areas near a fire that are prone to VLS is becoming a major input to effective incident planning. 
Near Real-time Remote sensing data: These fall into four types: weather radar, airborne, geostationary satellite, and near-polar orbiting satellite.

Weather radar reflectivity data were from BoM radars at Bairnsdale, Wagga, Captains Flat, Sydney and Williamtown. It has now been established that radar echotops, Fire Radiative Power and rate of burning of area can be well correlated (Peterson, et al., 2021). This correlation permits better interpretation of all data involved.

Linescans from NSW Rural Fire Service were acquired from cross-track scanners on aircraft. Ground resolution depended on flight height. They used the Airborne Thematic Mapper, based on the sensors on LandSat satellites. With the ability to schedule flights for times when they are most needed, linescans are the most operationally valuable source of detailed imagery.

Satellite imagery from the Advanced Himawari Imager on the Himawari- 8 geostationary satellite provide kilometre scale or better data every 10 minutes over a range of frequencies: Red/Green/Blue, Near InfraRed, Water Vapour, and thermal InfraRed. Subsets of this have been acquired for critical events. Animations of subsets provide a unique overview of complex fire patterns. Super-Rapid Scan-mode data were provided $(\mathrm{BoM})$ in late January - early February as well. Higher resolution imagery was acquired from near-polar orbiting satellites. Sentinel 2 products are equivalent to linescans but were available typically every three days. Landsat imagery have even longer repeat times. VIIRS and MODIS imagery, from four satellites, was acquired from both daytime and night-time overpasses every day. The VIIRS Day Night Band provided the only nighttime visible satellite imagery source and was able to resolve nocturnal fire progress on clear nights.

Hotspots are pixels classified as likely to be showing a fire due to their overall spectral signatures. Datasets include satellite metadata as well as estimates of Fire Radiative Power (MW). Hotspots have long been used from the MODIS sensors on the Terra and Aqua satellites and have increasingly been used from the VIIRS sensors on SUOMI-NPP and NOAA-20 satellites. NASA's Fire Information for Resource Management System (https://firms.modaps.eosdis.nasa.gov/) was the source of data.

Analytical satellite products: Some important products are produced by running the bands of satellite imagery (including those of specialist science satellites) though algorithms. The CALIOP sensor on the Calipso satellite (https://www-calipso.larc.nasa.gov/) uses a LIDAR to analyse the content and structure of the atmosphere beneath its orbit. The degree of backscatter and polarisation is used to classify the aerosol producing the backscatter and its vertical structure. The OMPS sensors on the SUOMI-NPP and NOAA 20 satellites, designed to measure ozone, also measure atmospheric aerosol loads, as the Aerosol Index. AI is useful for tracking plume advection, and for determining or confirming where detected aerosols have come from. As required, these were acquired to assist with analysis of fire and plume dynamics. Normalised Difference Vegetation Index images were important for assessing landscape flammability. Normalised Difference Burn Index images were important for assessing fire burn intensity.

Contextual data: These came from a wide range of sources (mainly BoM) and include: river flow depths (m); bushfire drought index ( $\mathrm{mm}$ on a 0 to $200 \mathrm{scale}$ ); sea surface temperature anomalies (SSTAs) from averaged satellite data; climate outlook metrics such as Southern Oscillation Index, Indian Ocean Dipole, Southern Annular Mode, \& Madden-Julian Oscillation; \& NDVI. These help set initial conditions for predictive model applicability. Fire occurrence requires "hot, dry, and windy" conditions. For escalated fires, these further typically reflect drought levels and heatwave events. These originate in SSTAs that are of sufficient scale to alter synoptic circulations. Drought affects both the soil and the vegetation, which can be measured in various ways. SSTAs can be forecast, and are inputs to numerical weather prediction models, but their effects are difficult to isolate.

Fires: An essential foundation dataset is the near real-time identification and mapping of all BUFEs and pyroCbs, and their interlinkages both for bushfire operational purposes and as part of an international collaboration looking at pyroCbs. This used many of the datasets described above. This process also identified fire areas that were not BUFEs.

\section{EXAMPLE RESULTS}

Analyses from PEBBS are being used for a range of current studies. Some interim examples are shown below.

\section{Example 1 - pressure patterns:}

Understanding synoptic pressure patterns and their effects on fire evolution is a key goal. In areas of complex terrain there can be significant local influences on the detailed weather, especially wind vectors. Fig. 1 shows an example of this, for $4^{\text {th }}$ January 2020. This was one of the most complex fire days on record. Many of the differences between the QNH patterns and the MSLP pattern reflect the higher terrain (the Southern and 
Northern Tablelands). However, many of the coastal influences caused unprecedented fire dynamics, such as major fire runs to the northeast in the low pressure area on the coast on the NSW-Victorian border. Pressure patterns are key to assessing the presence of ascending or descending air masses.

\section{Example 2 - smoke depths:}

CALIPSO curtain data, showing the maximum height at which aerosols backscattered the signal from the satellite, such as that shown in Fig. 2, covering passes over south-eastern Australia, were used to generate the time series plots in Fig. 3. Those show a transition from descending air mass events in the first half to ascending air mass events later, which also show a different relationship between day and night depths.
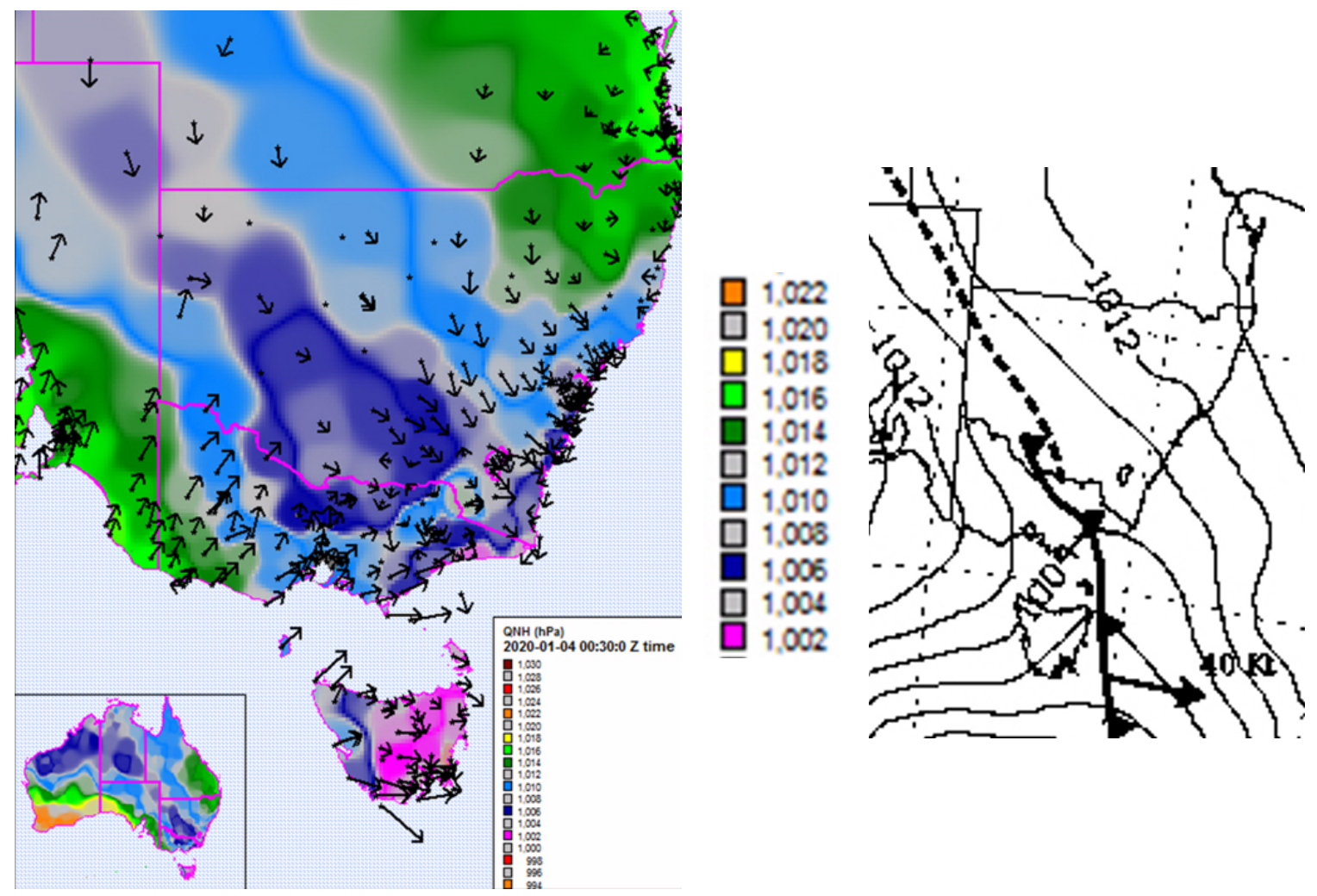

Figure 1. Thematic map of QNH pressure patterns and wind vectors (202001040030U, left) and MSLP pattern (202001040000U, right). Note that they are in different map projections.

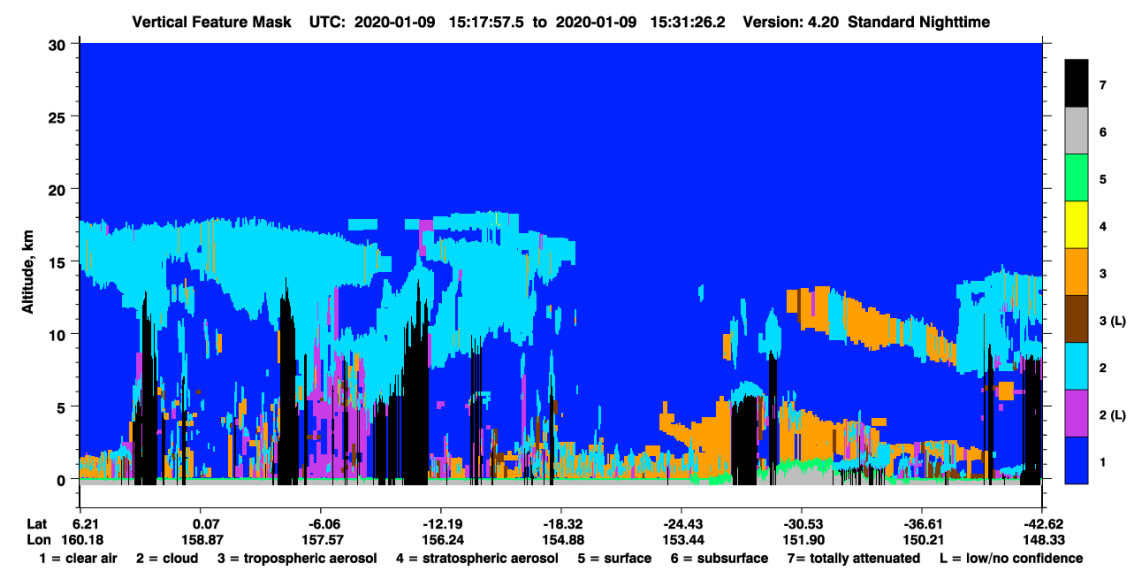

Figure 2. Example of a night-time Calipso LiDAR curtain, for 9 Jan 2020. Note tropospheric aerosol (orange, 3) up to $12 \mathrm{~km}$ ASL. 


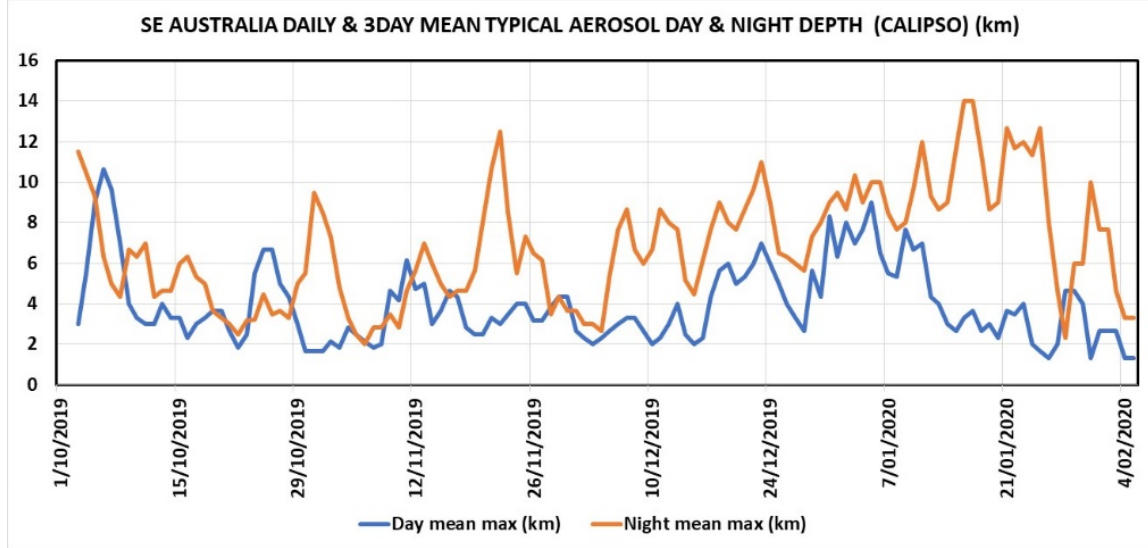

Figure 3. Time series of aerosol depth.

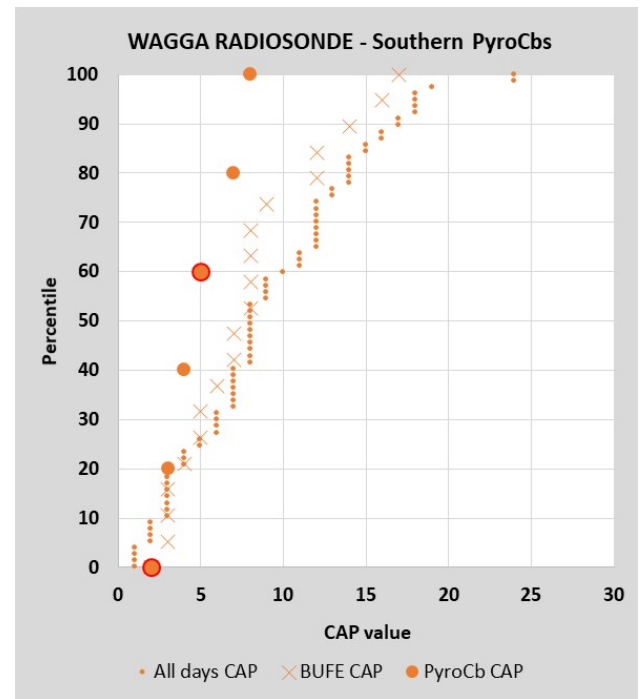

Figure 4. Comparison of observed CAP values for Wagga for all observations, those associated with one or more BUFEs, and those associated with one or more pyroCbs.

\section{Example 3 - convective caps:}

The convective cap (CAP) indicates the amount of resistance that a rising smoke plume will meet as it tries to rise past the LCL. This resistance is usually due to an inversion, where for some vertical distance the temperature increases with height. Fig. 4 shows CAP data derived from radiosonde flight data. The three sets of points are for (1) all flights, (2) flights matched to BUFE events, and (3) flights matched to pyroCb events. This shows that pyroCbs occur with CAP under $8^{\circ} \mathrm{C}$, whereas BUFEs in a synoptic pattern indicating a descending air mass can occur under much larger CAPs, highlighting a fundamental difference between the two types of BUFE. Note that the two enhanced pyroCb dots in Figure 4 are for events where remotely sensed data on the dynamics of plume bases clearly indicate large area burnouts under the authorised incident action plans then in place at times when CAP was at or below $5^{\circ} \mathrm{C}$.

\section{Example 4 - VIIRS hotspot transect:}

A curvilinear transect along the spine of a $26 \mathrm{~km}$ main run of a BUFE is shown below in Fig. 5. It contained 242 hotspots. The hotspot FRP values were aggregated (summed) along that transect into $0.01^{\circ}$ segments. The FRP trace along the transect is shown in Fig. 6. This indicates that the hotspots dataset from the two VIIRS sensors provides a reasonable snapshot of the BUFE's behaviour at the time of overflight (half-way between midnight and sunrise). There is even a likely resolution of a major spotfire about $3 \mathrm{~km}$ ahead of the main run. The novel understanding provided by analyses such as this aids in tuning predictive models. The Y-axis, in Megawatts, is a reminder of the extraordinary power of large BUFE runs. 


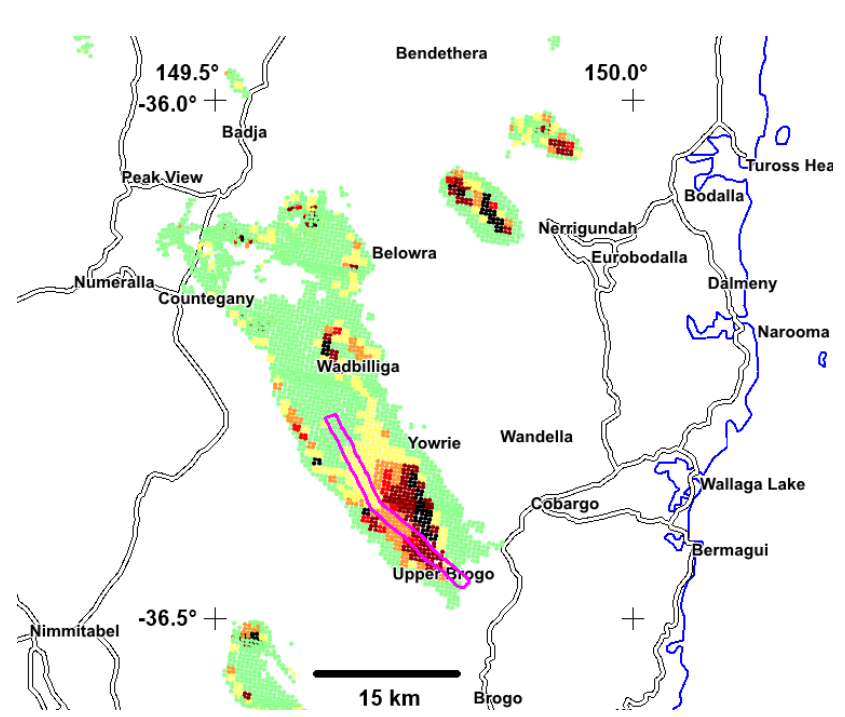

Figure 5. Upper Brogo VIIRS hotspot transect, night of 30/12/2019. Prevailing winds were from the north-west (upper left).

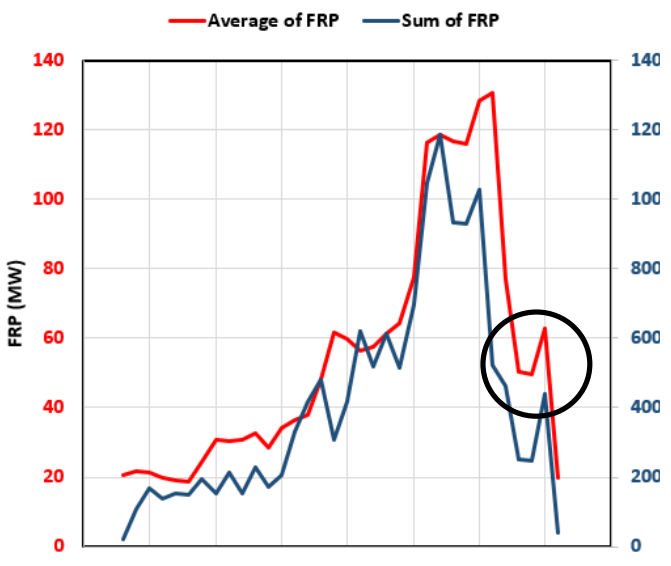

Figure 6. Upper Brogo transect results. The highlight shows a potential large spotfire ahead of the main front.

\section{APPLICATION}

Regional Patterns: For a broad spatio-temporal domain, there can be trends and gradients in the datasets. Within these it is possible to establish when BUFEs do or do not occur. The typical evolution of these trends can be used to refine predictions. This permits better strategic planning at the incident and regional level. For example, the data show that BUFEs and pyroCbs are preceded by a pattern of river flow drying that indicates cessation of deep soil drainage. This is a suitable boundary condition for applying BUFO2.

Percentile: The distribution of all observations can be compared to that of the subset corresponding to events (either as the closest spatio-temporal fit or as a key daily observation). differences yield valuable clues to when events occur or do not occur. As seen in Figure 4, a convective cap over $8^{\circ} \mathrm{C}$ in an ascending air mass rules out pyroCb formation. This matched the $50 \%$ ile during Black Summer - but that value may be much lower in a typical future fire season or different due to climate change.

Timeline: A time-series may exhibit trends that coincide with outbreaks of events. The diurnal cycle of fire weather indicates the window within which fuel moisture will be low enough to support easy spotting.

Fire: Unlike normal fire behaviour modelling, BUFO2 looks for fire on VLS prone landforms at times when other factors are forecast to occur. Where fire will be at such times is at least partly under the control of incident management teams. By modelling the results of certain tactical decisions. It may be possible to select one with the most desirable outcome from the perspective of avoiding the occurrence of VLS.

\section{DISCUSSION}

PEBBS is driving the development of BUFO2, a new predictive tool for BUFEs. Where BUFO was based on case studies and theoretical concepts, BUFO2 has a far more statistical foundation based on a wide range of real-world occurrences. Case studies have not given insight into why some fires do not develop BUFEs. Similarly, there is little if any case study work done on Australian BUFEs in a descending air mass, although studies in places like California (BUFEs under Santa Ana winds) and Europe (BUFEs under foehn winds with various names) may prove useful.

BUFO will benefit from: improved boundary conditions; new knowledge of the key conditions to model; and a better ability to exclude fires. PEBBS will also guide the research needed for future upgrades to BUFO2.

It is also likely that during any future outbreaks like this, a coordinated collection of data will both maximise productivity of the effort and ensure the best ability to create near real-time intelligence products to support fire operations. This will require an on-going collaboration to ensure the best possible sets of data are collated and archived. 


\section{ACKNOWLEDGEMENTS}

The author has no conflict of interest. Much of the work was done in support of operations for the ACT Emergency Services Agency.

\section{REFERENCES}

Di Virgilio, G., Evans, J.P., Blake, S.A.P., Armstrong, M., Dowdy, A.J., McRae, R., 2019. Geophysical Research Letters 46, 8517-8526. https://doi.org/10.1029/2019GL083699.

McRae, R.H.D., Sharples, J.J., 2013. A process model for forecasting conditions conducive to blow-up fire events. Proceedings, 2013 MODSIM Conference, Adelaide.

McRae, R.H.D., Sharples, J.J., 2014. Forecasting conditions conducive to blow-up fire events CAWCR Research Letters, 11, 14-19.

McRae, R H D, Sharples, JJ, Fromm, M., 2015. Linking local wildfire dynamics to pyroCb development. Natural Hazards and Earth Systems Sciences, 15, 417-428.

Peterson, D.A., Fromm, M.D., McRae, R.H.D., Campbell, J.R., Hyer, E.J., Taha, G., Camacho, C.P., Kablick, G.P., Schmidt, C.C., DeLand M.T., 2021. The unprecedented pyrocumulonimbus super outbreak in Australia at the dawn of 2020: cause and perspective. npj Climate and Atmospheric Science 4, 38. https://doi.org/10.1038/s41612-021-00192-9.

Sharples, J.J., Cary, G.J., Fox-Hughes, P., et al., 2016. Natural hazards in Australia: extreme bushfire. Climatic Change, DOI 10.1007/s10584-016-1811-1. 